\title{
Potential effect of ocean pollution on human health, marine species, and health of the planet: adopting a planetary approach to a planetary problem
}

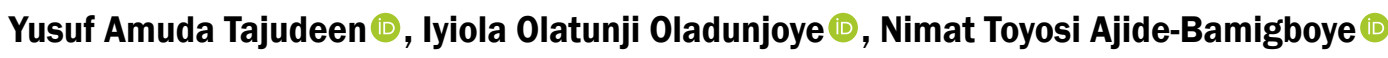

Department of Microbiology, Faculty of Life Sciences, University of Ilorin, Nigeria

Over the years, ocean pollution - which can be described as a complex combination of pollutants including plastics, toxic metals, oil spills and petroleum wastes, pharmaceutical wastes, agricultural run-off, urban and industrial wastes, and microbial wastes - has become an increasingly growing global threat due to its devastating impact on human health and marine species by causing the death of millions of people and thousands of marine species per annum across the world [1, 2]. This threat has been on the rise since the beginning of the Agricultural Revolution and Industrial Revolution that brought about increased release of agricultural run-off containing fertilizers, animal wastes (that contains antibiotics residue) as well as industrial wastes such as toxic metals and chlorinated petrochemicals into the ocean by anthropogenic activities, thus, posing a threat to marine species, the human health, and planetary health - as a result of collapsed of fishing ground and reduced livelihood of populations in the coastal areas. The rising detrimental effect of ocean pollution on the health of humans, marine species, and the health of the planet can best be addressed effectively from a planetary health perspective.

Human activities including overfishing and environmental disruptions are important factors causing changes in climatic conditions such as the drastic increase in global ocean temperatures, increased occurrence of extreme weather events such as heatwave that could result in melting of the glacier, and ocean acidification from increased absorption of $\mathrm{CO}_{2}$ emission by the ocean [3]. Changes in climatic conditions could also drive pathogenic microorganisms, particularly bacteria into the water body causing a significant threat to human health due to the spread of infectious diseases such as cholera during contact with water contaminated by Vibrio cholerae [4]. Increased ocean pollution has been revealed to occur from land-based sources, evidently, an estimated $80 \%$ of ocean pollution originated from landbased sources while the remaining $20 \%$ has been linked with discharge and wastes from the offshore industry, marine shipping, and unregulated wastes (solid and liquid) disposed at the sea [5]. However, this global threat of ocean pollution can hinder the attainment of Sustainable Development Goals (SDGs) like SDG 14 which seek to reduce marine pollution from land-based sources and other sources towards protecting the lives below water (marine species), SDG 6 which aims to ensure clean water and sanitation by minimising the release of toxic chemicals in the water body, and SDG 3 which advocate for the improvement of human health and well-being by mitigating the threat occurring in their environment.

Pollution of the ocean by plastics is on the rise and about 4.8-12.7 million metric tons of plastic are dumped into the ocean per annum [2]. The accumulation of undigested macroplastic wastes including bottle caps and small bottles in the gastrointestinal tract of marine species such as fishes and seabirds result in increased mortality in these animals. Microplastics ( $<5 \mathrm{~mm}$ in diameter) can cause damages to the tissues and cells of marine species while nanoplastics ( $<1 \mu \mathrm{m}$ in diameter) can penetrate the gut lining, bloodstream, and organs of marine species when ingested, leading to organs damage and death [6]. Human consumption of seafood contaminated with plastic residues could lead to various health threats such as the threat of non-communicable diseases like cancer; however, there are fewer studies on this aspect. Chemical additives such as plasticizers and other organic chemicals that could be absorbed by plastics can pose a considerable threat to marine species and human health - through the food chain [7].

Dr. Yusuf Amuda Tajudeen, Department of Microbiology, Faculty of Life Sciences, University of Ilorin, Ilorin, Nigeria, e-mail: tajudeenamudayusuf@gmail.com 
Another important source of ocean pollution is the unregulated disposal of pharmaceutical wastes such as antibiotics from sewage effluent, aquaculture, and animal husbandry. These wastes enormously find their way into the aquatic environment where they can undergo biotic and abiotic transformation into suspended particulate matter and sediment. In most cases, the suspended particulate matter is accumulated in the tissue of marine species which when consumed by humans can result in antibiotic-resistant infections [8]. In their study, Rose et al. [9] revealed the increased spread of antibiotic resistance in fishes, marine mammals, and seabirds in coastal water in North Eastern United States.

General shipping and industrial activities have led to increased pollution of the marine environment by petroleum wastes and oil spills containing toxic hydrocarbons that have a detrimental effect on human health and marine species. It has been reported that the toxicity of hydrocarbons increases when ingested by marine species due to the activation of the polycyclic aromatic hydrocarbons in their liver causing carcinogenic effects and a significant mortality level [10]. Consequently, inhalation of hydrocarbons by these marine species can result in respiratory tract irritation and narcosis due to the high volatility of the compounds, the hydrocarbon compounds, when inhaled, have also been reported to pose a long-term health effect to humans [11]. Runoff containing spilled mercury from the metal mining industry is one of the most common toxic metals with a high accumulation rate by marine species, the consumption of fishes and marine animals contaminated with mercury can lead to cardiovascular threats and brain damages in man [12].

Microbial pollution in the marine environment usually occurs when toxin-producing algal species dominate the ocean, thus, leading to the formation of algal blooms. These algal blooms tend to limit inorganic nutrients and dissolved oxygen available to marine animals and this could lead to their deaths. Through the consumption of seafood contaminated with an algal bloom, humans become exposed to the toxin produced by algal species causing diseases and death [13].

In conclusion, the increased ocean pollution being demonstrated to have a devastating effect on the human health, marine species, and the health of the planet as a result of interdependency that exists, can best be addressed from a holistic view like planetary health. It is important to note that there is a paucity of research on this aspect and we recommend more research to be conducted in the spectrum of planetary health, and through the multisectoral and inter- disciplinary collaboration amongst researchers (ecologists, climate scientists, microbiologists, marine biologists, and public health scientists) evidenced-based result targeting at fostering law and policies that limit ocean pollution can be implemented towards protecting the health of humans, animals, and the planet.

\section{Conflict of interest: None declared}

\section{REFERENCES}

1. Statista (2020). Study: Pollution Kills 8.3 Million People Annually. https://www.statista.com/chart/20360/premature-pollution-related-deaths/ (September 9, 2021).

2. Medical News Today (2020). What effect does water pollution have on health? . www.medicalnewstoday.com/articles/water-pollution-and-human-health (September 9, 2021).

3. Gruber N, Clement D, Carter BR, et al. The oceanic sink for anthropogenic CO from 1994 to 2007. Science. 2019; 363(6432): 1193-1199, doi: 10.1126/science.aau5153, indexed in Pubmed: 30872519.

4. Lipp EK, Huq A, Colwell RR. Effects of global climate on infectious disease: the cholera model. Clin Microbiol Rev. 2002; 15(4): 757-770, doi: 10.1128/CMR.15.4.757-770.2002, indexed in Pubmed: 12364378.

5. GESAMP. Sources, fate and effects of microplastics in the marine environment: A global assessment. 2015.

6. Law KL. Plastics in the Marine Environment. Ann Rev Mar Sci. 2017; 9: 205-229, doi: 10.1146/annurev-marine-010816-060409, indexed in Pubmed: 27620829.

7. Rochman CM, Hoh E, Hentschel BT, et al. Long-term field measurement of sorption of organic contaminants to five types of plastic pellets: implications for plastic marine debris. Environ Sci Technol. 2013; 47(3): 1646-1654, doi: 10.1021/es303700s, indexed in Pubmed: 23270427.

8. Gaw S, Thomas KV, Hutchinson TH. Sources, impacts and trends of pharmaceuticals in the marine and coastal environment. Philos Trans R Soc Lond B Biol Sci. 2014; 369(1656): 20130572, doi: 10.1098/rstb.2013.0572, indexed in Pubmed: 25405962.

9. Rose JM, Gast RJ, Bogomolni A, et al. Occurrence and patterns of antibiotic resistance in vertebrates off the Northeastern United States coast. FEMS Microbiol Ecol. 2009; 67(3): 421-431, doi: 10.1111/j. 1574-6941.2009.00648.x, indexed in Pubmed: 19187217.

10. Ordinioha $B$, Brisibe $S$. The human health implications of crude oil spills in the Niger delta, Nigeria: An interpretation of published studies. Niger Med J. 2013; 54(1): 10-16, doi: 10.4103/03001652.108887, indexed in Pubmed: 23661893.

11. Saadoun I. Impact of oil spills on marine life. Emerging Pollutants in the Environment - Current and Further Implications. 2015, doi: 10.5772/60455.

12. Roman HA, Walsh TL, Coull BA, et al. Evaluation of the cardiovascular effects of methylmercury exposures: current evidence supports development of a dose-response function for regulatory benefits analysis. Environ Health Perspect. 2011; 119(5): 607-614, doi: 10.1289/ehp.1003012, indexed in Pubmed: 21220222.

13. Kudela R, Berdalet E, Bernard S, et al. Harmful algal blooms. In: a scientific summary for policy makers. Paris: IOC/UNESCO; 2015. 